\title{
STRESS AND CANCER IN DOGS: COMPARISON BETWEEN A POPULATION OF DOGS DIAGNOSED WITH CANCER AND A CONTROL POPULATION - A PILOT STUDY
}

\author{
Simona Cannas ${ }^{1}$, Greta Veronica Berteselli ${ }^{2}$, Patrizia Piotti ${ }^{3}$, Zita Talamonti ${ }^{1}$ \\ Elisabetta Scaglia ${ }^{1}$, Damiano Stefanello ${ }^{1}$, Michela Minero ${ }^{1}$, Clara Palestrini ${ }^{1}$ \\ IDipartimento Medicina Veterinaria (DIMEVET), \\ Università degli Studi di Milano, Via Celoria 10, 20133 Milano, Italy \\ ${ }^{2}$ via Giotto 20, 20060 Masate, Milano, Italy \\ ${ }^{3}$ Department of Psychology, University of Portsmouth, King Henry Building, \\ King Henry $1^{\text {st }}$ Street, Portsmouth, PO1 2DY, UK
}

Received 8 March 2016; Received in revised form 17 May 2016; Accepted 31 May 2016

\begin{abstract}
It is widely accepted that psychological stress and mental illness can compromise the function of the immune system. Clinical and epidemiological studies on humans recognized that specific psychosocial factors, such as stress, chronic depression and lack of social support are risk factors for the development and progression of cancer. Unfortunately, most of the animals studies on this subject are based on laboratory tests performed on mice. This retrospective cohort study aims to analyze the relation between stress and tumor in pet dogs, by evaluating and comparing the stress level in two groups of 69 dogs each, balanced for sex and age: the oncologic group consists of dogs diagnosed with cancer and the control group consists of healthy dogs. Our results show that, before the cancer diagnosis, more dogs in the oncologic group faced changes in their household and routine as opposed to the control group $(\mathrm{p}<0.05)$. More dogs of the oncologic group than the control group also showed signs of stress and anxiety, before the cancer diagnosis $(\mathrm{p}<0.05)$. As reported by their owners, these included attention seeking, hiding without a specific reason, following the owner around the house, hyper-vigilance, fear of fireworks and gunshots, biting, aggression towards other dogs, licking and chewing excessively parts of their body. Our results are aligned with the evidence from human research, indicating that dogs with cancer are significantly more likely to have shown signs of stress compared to the control dogs during their life.
\end{abstract}

Key words: dog, stress, tumor, problem behavior

\section{INTRODUCTION}

A considerable amount of studies demonstrate that negative psychological states, such as chronic stress, depression, social isolation, are associated with the down-regulation of the cellular immune response mediated by adrenergic and glucocorticoid

Corresponding author: Dr. Simona Cannas, $\mathrm{PhD}$

E-mail address: simona_cannas@hotmail.com

Present address: Dipartimento di Medicina Veterinaria (DIMEVET), Università degli Studi di Milano, Via Celoria 10, 20133 Milano, Italy Phone: 0039 3803185036; Fax: 00390250318030

Copyright: (C) 2016 Cannas S. This is an open-access article published under the terms of the Creative Commons Attribution License which permits unrestricted use, distribution, and reproduction in any medium, provided the original author and source are credited.

Competing Interests: The authors have declared that no competing interests exist.

Available Online First: 16 June 2016

Published on: 15 October 2016

http://dx.doi.org/10.1515/macvetrev-2016-0088 signaling, which increases the risk of developing diseases (1-7). Although there is no unanimity in the literature, results from both human and laboratory animal studies suggest that psychological factors and chronic stress may promote the onset and the progression of cancer $(6,8,9,10,11)$.

Stress is the general reaction of the organism when the homeostasis is altered by physical and psychological factors called "stressors" $(12,13)$. When in this state, the body activates physiological and immunological mechanisms: these modulate physical and behavioral functions aimed at adapting to the new situation and restore the initial homeostasis $(4,13,14,15)$. Stress and the immune system are therefore closely related. In fact, the stress response is thought to have evolved phylogenetically from a primitive humoral immune system, aimed to face internal or external challenges to the organism (16). 
The exchange of information, directly or through the neuroendocrine system, between brain and immune system creates a "psychoneural-endocrine-immune circuit" $(17,18)$. The consequence is that when the homeostasis cannot be restored, the prolonged effect of stressors may induce an immune dysregulation modulated by the endocrine system. Particularly, stress can inhibit the immune-surveillance activity of $\mathrm{T}$ cells and Natural Killer cells (NK), which intervene in the immune-surveillance against tumors $(19,20)$. Stress hormones such as cortisol, catecholamine and other endocrine mediators can promote proliferation of neoplastic cells, and inhibit the mechanisms that eliminate altered cells, such as apoptosis and DNA repair systems. Cortisol and catecholamine can also facilitate tumor development mechanisms, such as angiogenesis and metastasis $(6,21,22,23)$. Therefore, while the stress response is not thought to cause tumors directly, it appears that chronic stress can promote the incidence and progression of cancer, with similar mechanisms in humans and animals such as the domestic dog. This relies on the relationships between stress system, immune system and carcinogenic mechanisms $(21,24)$.

A large amount of evidence also demonstrated that anxiety, phobia, fear, depression and chronic stress induces changes in the neuroendocrine system in human beings $(1-7,32)$, and that such changes also occur in pet dogs showing behavioral problems $(15,25,26,27,30,31)$.

Several problem behaviors are recognized as biological indicators of poor welfare in dogs because they can be symptoms of chronic stress $(15,28,40)$. However, it should be considered that though the stress system acts in the same way in all individuals, coping to stress depends on several factors as individual and genetic differences, developing phases, life experiences and household $(15,27,41)$.

There is evidence to support the use of domestic dogs as models for the study of the relation between stress and cancer from a comparative point of view $(34,35)$. As for humans, stress can become detrimental for dogs' wellbeing when it becomes chronic or the animal is unable to cope and restore homeostasis $(15,25,26)$. Anxiety-related disorders are among the most common behavioral problems in pet dogs, and their behavioral manifestations are indeed considered good indicators for monitoring the presence of stress $(15,25,26,27,28)$. Additionally, the stress system is controlled by the same physiological mechanisms in dogs and humans (4, 12, 29, 30), and most of dogs' behavioral problems have neuropathological bases similar to that of certain psychological disorders in humans such as depression, anxiety and phobias $(27,31)$. For 202 example, dogs affected by anxiety related disorders have high cortisol blood levels similar to humans $(28,32)$. Finally, several types of the spontaneous tumors occurring in pet dogs share numerous features with those of humans, such as genetic characteristics, histopathological appearance, biological behavior, molecular targets and response to conventional cancer therapy $(33,34,35)$.

The current retrospective cohort pilot study aims to analyze the relation between stress and cancer in pet dogs by evaluating and comparing the stress level in two groups: one group consisting of dogs diagnosed with malignant tumors, the other group consisting of healthy control dogs (i.e. without oncological diagnoses or other medical diagnoses).

\section{MATERIAL AND METHODS}

\section{Subjects}

Two groups of 69 dogs each, balanced for sex and age, were included in the study. The first group (hereafter named "oncologic group") consisted of dogs with a previous diagnosis of a spontaneous malignant tumor. Dogs in this group were recruited through the Department of Veterinary Science and Public Health at the Veterinary University from June 2006 to May 2009. The inclusion criterion was a cytological or histological definitive diagnosis of malignant neoplasia. The second group ("control group") consisted of healthy dogs with no signs of clinical diseases, and not previously affected by tumors. Subjects in the control group were recruited from personal contacts trough the Hospital, during the same time frame. Oncologic and control dogs underwent a physical examination, and had a complete blood count and biochemistry panel performed.

\section{Data collection}

Dogs' owners were asked to complete a questionnaire including their dog's demographic information and behavioral history, as well as information on the dog's physical and social environment. For the oncologic group, owners were explicitly required to provide information about the dog's behavior and lifestyle before the diagnosis of neoplasia.

Through open questions, owners provided information about the signalement, medical and behavioral history of their dog. The other sections of the questionnaire were composed of multiple choice questions: a first part provided information about home environment, animal management, age of the animal (current age, and age at acquisition), sex, reproductive status (intact or neutered/spayed), 
number of adults and children in the household (people older than 18 years were considered adults), origin of the dog (breeder, pet store, shelter, rescue, family, friends or stray), and number of other pets in the household. A second part provided information about whether the dog had displayed specific signs compatible with behavioral problems, such as fear, anxiety, separation anxiety, aggression or compulsive disorders.

\section{Statistical analysis}

Answers to the questionnaire were scored and the data were entered into Microsoft Excel (Microsoft Corporation 2010) and analyzed with SPPS statistical package (IBM SPSS Statistic 21). Descriptive statistics (relative proportions, minimum and maximum values, median, mean and standard deviations) were calculated to provide a general description of the two experimental groups.

Any differences in behavior, management and environment between the oncologic and the control group, were verified using a ChiSquare test. Differences were considered to be statistically significant if $\mathrm{p} \leq 0.05$. A Decision Tree model was performed as descriptive means to identify the variables, and their probability of predicting the development of tumors in pet dogs.

\section{RESULTS}

Dogs were 12 intact and 37 spayed females, 5 neutered and 15 intact males ranging in age from 2 and 16 years (mean 8,29 $\pm 2,6$ years) for both groups.

In the oncologic group $62 \%$ of dogs were pure breeds; the remaining $38 \%$ were mixed breeds. In the control group, $56 \%$ of dogs were pure breeds, while $44 \%$ were mixed breeds. Breeds were divided into groups according to the Official Dog Breeds List of the Italian Kennel Club: Sheepdogs and Cattle dogs [1], Pinschers, Schnauzers and Molossers [2], Terriers [3], Dachshunds [4], Spitz and primitive type dogs [5], Hounds and blood tracking dogs [6], Pointing dogs [7], Retrievers, search dogs, water dogs [8], Companion dogs [9], Greyhounds [10]. More information about breeds is specified in Table 1. The oncologic diagnoses are summarized in Fig. 1.

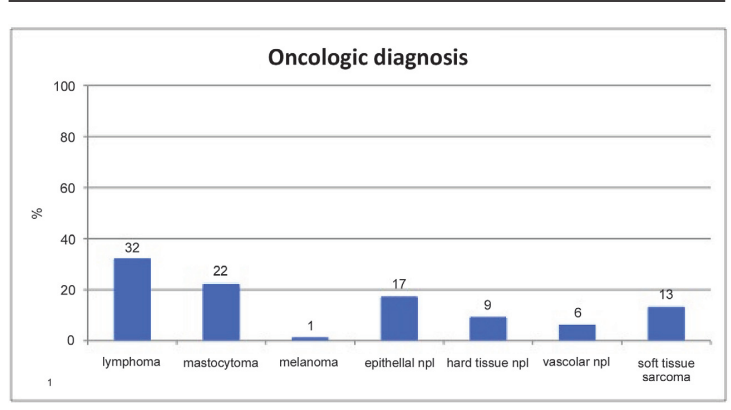

Figure 1. Oncologic diagnosis

Twenty-five per cent of the dogs in both groups were adopted before 7 weeks of age, about $35 \%$ between eight and 13 weeks, $7 \%$ between 6 months and one year and about $15 \%$ after 1 year of age. The remaining 53\% were either younger than 7 weeks or older than 1 year, when adopted.

In the oncologic group, most dogs (39\%) were adopted from private non-breeders, followed by $23 \%$ adopted directly from breeders. The remaining dogs were adopted from a pet store $(1 \%)$, from local shelter $(15 \%)$ or were strays $(15 \%)$. In the control group, $12 \%$ of dogs were adopted from non-breeders and $36 \%$ from breeders. The remaining control dogs had similar origins as the oncologic dogs with $7 \%$ from pet stores; about $15 \%$ from shelters and another $15 \%$ were strays.

At the time of adoption, about half of $\operatorname{dog} s$ from both groups were with the mother and other littermates; $29 \%$ of oncologic dogs and $17 \%$ of control dogs were alone when adopted (which includes dogs adopted as puppies and adults). In both groups, about $60 \%$ lived their lives with three or more people in the household and about $13 \%$ lived with only one owner.

Fifty-four percent of oncologic dogs and 27\% control dogs were the only pet in the household. Of the remaining oncologic dogs, $25 \%$ lived with other dogs, $12 \%$ lived with cats, $10 \%$ lived with another dog and cat, and $4 \%$ lived with other animal

Table 1. Percentage of dog breeds in the two groups

\begin{tabular}{lccccccccccc} 
& $\begin{array}{c}\text { Group } \\
\mathbf{1}\end{array}$ & $\begin{array}{c}\text { Group } \\
\mathbf{2}\end{array}$ & $\begin{array}{c}\text { Group } \\
\mathbf{3}\end{array}$ & $\begin{array}{c}\text { Group } \\
\mathbf{4}\end{array}$ & $\begin{array}{c}\text { Group } \\
\mathbf{5}\end{array}$ & $\begin{array}{c}\text { Group } \\
\mathbf{6}\end{array}$ & $\begin{array}{c}\text { Group } \\
\mathbf{7}\end{array}$ & $\begin{array}{c}\text { Group } \\
\mathbf{8}\end{array}$ & $\begin{array}{c}\text { Group } \\
\mathbf{9}\end{array}$ & $\begin{array}{c}\text { Group } \\
\mathbf{1 0}\end{array}$ & $\begin{array}{c}\text { Mixed } \\
\text { breed }\end{array}$ \\
\hline $\begin{array}{l}\text { Oncologic } \\
\text { group }\end{array}$ & $10 \%$ & $30 \%$ & $3 \%$ & 0 & $1 \%$ & 0 & $9 \%$ & $9 \%$ & 0 & 0 & $38 \%$ \\
$\begin{array}{l}\text { Control } \\
\text { group }\end{array}$ & $10 \%$ & $6 \%$ & $10 \%$ & 0 & $4,5 \%$ & $3 \%$ & 0 & $18 \%$ & $4,5 \%$ & 0 & $44 \%$ \\
\hline
\end{tabular}


species. The distribution of remaining control dogs was similar to the oncologic group. No cohabitation problems were reported in $90 \%$ of both groups. In the oncologic group, $78 \%$ of the dogs experienced changes in the household: $23 \%$ were permanently separated from a family member, e.g. because of death, $12 \%$ arrival of a new family member, e.g. newborns or marriages, $4 \%$ moving house, $4 \%$ substantial changes in the daily routine, e.g. changes in owners' working shifts, $35 \%$ more than one change. $58,1 \%$ of dogs belonging to the oncologic group and $41,9 \%$ of dogs belonging to the control one had changes in the household $(\mathrm{p}<0.05)$ (Fig. 2).

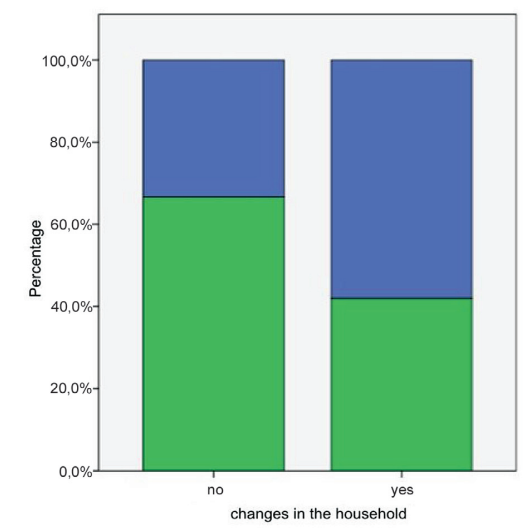

E- oncologic group
control group

Figure 2. Percentage of dogs that had changes in the household $(\mathrm{p}<0.05)$

Lack of daily routine, for feeding time, walks and/or interaction with owners, was significantly higher in the oncologic group (84.4\%) than in the control group $(15,6 \%)(\mathrm{p}<0.05)$ (Fig. 3).
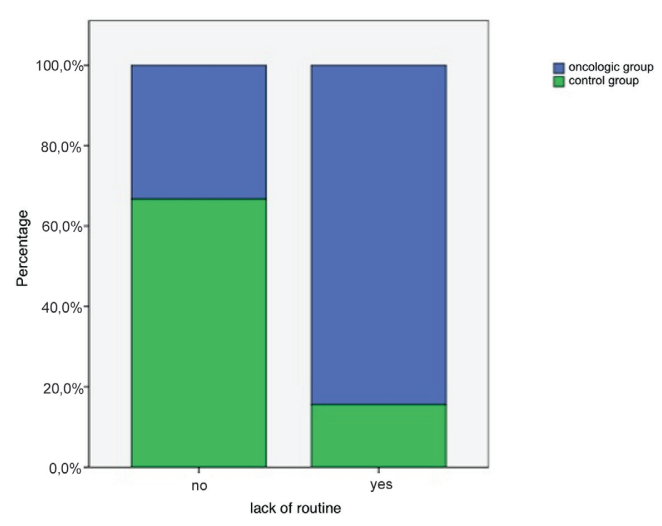

Figure 3. Percentage of dogs that had a lack of routine $(\mathrm{p}<0.05)$

The percentage of surgery or a traumatic event before the diagnosis of neoplasia was $63,5 \%$ in the oncologic group and $36,5 \%$ in the control group $(\mathrm{p}<0.05)$ (Fig. 4).

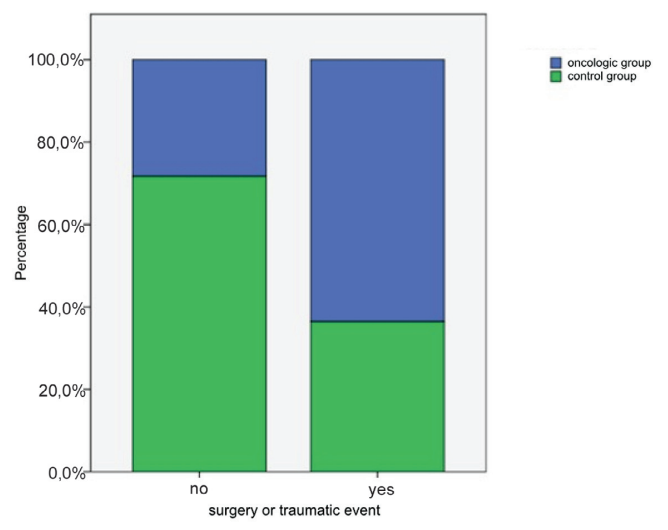

Figure 4. Percentage of dogs that had surgery or traumatic event $(\mathrm{p}<0.05)$

Attention seeking behavior and following the owners everywhere around the house were significantly higher in the oncologic group (attention seeking 62\%; following 68\%) with respect to the controls (attention seeking 38\%; following $32 \%)(\mathrm{p}<0.05)$. The percentage of dogs hiding without a specific reason was $75,6 \%$ in the oncologic group and $24,4 \%$ in the control one $(\mathrm{p}<0.05)$. Furthermore, oncologic dogs proved to be significantly more vigilant $(58,8 \%)$ and fearful of fireworks and gunshots $(62 \%)$ than controls (hypervigilance $41,2 \%$; fear of fireworks and gunshots $38 \%)(\mathrm{p}<0.05)$.

$67 \%$ of oncologic dogs and $33 \%$ of controls showed aggressive behaviors towards people $(p<0.05)$. Similarly, $68 \%$ of dogs of the oncologic group as opposed to $32 \%$ belonging to the control one showed aggression towards other dogs $(\mathrm{p}<0.05)$.

The percentage of dogs that lick and chew excessively parts of their body was significantly higher in the oncologic group $(74 \%)$ than in the control group $(26 \%)(p<0.05)$. These results are summarized in Fig. 5.

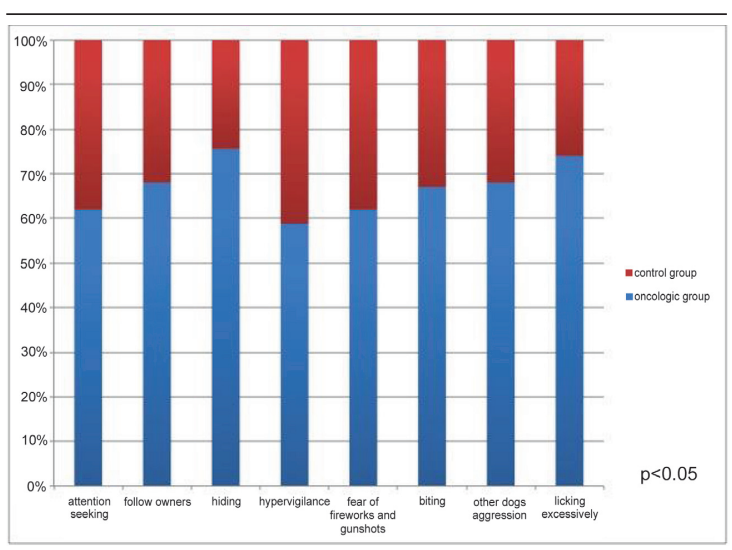

Figure 5. Percentage of dogs showing different stress-related behaviors 
The Decision Trees identified the lack of routine as the factor that mainly predicts the dependent variable considered (tumor prevalence) $(\mathrm{p}=0.000$; CHI-Square=31.689; $\mathrm{df}=1$ ).

\section{DISCUSSION}

The two groups of dogs in our study are homogenous regarding sex, age and source of the subjects. This is relevant because these variables can play an important role in veterinary oncology, where in subjects older than 7 years and in certain breeds the incidence of malignant neoplasia is more prevalent (36).

We found that significantly more dogs of the oncologic group, as opposed to the control group, experienced substantial changes in the household. Environmental or social factors unpredictability intervenes in the development of behavioral disorders. When an individual is unable to adapt to a new or unpredictable environment, stress becomes chronic, thus leading to physical and behavioral consequences $(4,30,37,38)$. This is supported by evidence in the human literature, where the loss of a family member or changes in living conditions are particularly stressful situations which are also associated to an increased prevalence of tumors $(2,3,4)$.

From the results of this study, it is possible to conclude that more dogs in the oncologic group have been exposed to major stress events as opposed to the control group. Pet animals are often confronted with unpredictable and uncontrollable life events, such as changes in the social core group (e.g. children leaving the house, babies being born, divorce, etc.), changes in the physical environment (e.g. moving to another place), or both. Unpredictable major life events can lead to gross behavioral dysfunctions, such as increased stress and (pathological) anxiety (39).

A higher number of dogs in the oncologic group underwent a surgery or experienced a traumatic event than in the control group. This is interesting because several aspects of surgery are implicated in immunosuppression, e.g. anesthetic and analgesic drugs, hypothermia, tissue damage, blood loss and transfusion, nociception, pain, and perioperative anxiety and stress (22). There is also empirical evidence, from animal and human studies, of the promotion of metastasis induced by stress and surgery, with specific reference to the mediating role of cell-mediated immunity (22).

The oncologic dogs in this study also showed significantly more behaviors that are signs of stress and anxiety $(40,41,42)$ and that can be related with behavioral disorders $(15,27,25,26)$.

Finally, the factor that discriminated the two groups, marking out the oncologic group, was the lack of routine, which was the better predictor variable of the Decision Trees.

For dogs, it is essential to have a daily routine related to time of feeding, walking and interaction because this leads to a predictable environment. Situations characterized by lack of routine or unpredictability changes of social and physical environment can be stressors and a triggering event to onset behavioral problems, especially in those subjects that are not able to show correct behaviors to cope in stress situation $(15,26,39,43,44)$. The resulting chronic stress could interfere with neuroendocrine and immune processes altering the organism's defenses, increasing the risk for several conditions, including cardiovascular disease, type 2 diabetes, mental health complications, and some cancers $(45,46)$.

The effects of behavioral stress on tumor initiation and progression are complex and should be analyzed in the context of relevant microenvironment biology $(6,21)$.

Our study shows several limitations. Some breeds may be both more cancer prone and more prone to stress, but that does not prove causality and in our study it was not possible to evaluate eventual breed bias. The major limitations of this work is that, being retrospective, is very difficult to make any conclusions regarding the evaluation of specific previous behaviours in the dogs' life, but our results are aligned with the evidence from human research, indicating that dogs with cancer are significantly more likely to have shown signs of stress in their previous life compared to control dogs.

In this study, we focused on the interaction between bio-behavioral factors and cancer in pet dogs. In light of the results of our study, it is clear that spontaneous tumors in companion animals offer a unique opportunity to investigate the relationship between stress and cancer and that dogs are good models for human cancer biology. The relatively high incidence of some types of cancer, similarity in biologic behavior, large body size, and comparable responses to cytotoxic agents are some of the similarities in dogs and humans $(34,35)$. For the aforementioned reasons, further research should be established in order to obtain additional information regarding the link between tumor and stress. Specifically, we suggest that future studies should focus on the analysis of the possible application of behavioral, neuroendocrine and immune stress markers to this area of research, such as cortisol, serotonine, dopamine, $\operatorname{IgA}$, lysozyme $(28,47,48$, $49,50)$. It would be also beneficial to increase the 
sample size in order to focus on a specific type of neoplasia: for example, canine lymphoma is considered the most suitable type of canine tumor in the field of comparative oncology (35).

The comparative study of the effect of stress on tumors is promising. In addition to the increasing understanding of the cancerogenesis process, it offers, in the long term, opportunities for innovative therapeutic interventions. These could be based on combined behavioral and pharmacological approaches, aimed at tumor-supporting immuneneuroendocrine processes; such approaches may be integrating, or being used in combination with conventional therapies $(6,51)$.

\section{ACKNOWLEDGEMENT}

The authors thank all the owners and dogs that participated as volunteers.

\section{REFERENCES}

1. Leonard, B.E., Song, C. (1996). Stress and the Immune System in the Etiology of Anxiety and Depression. Pharmacol. Biochem. Behav. 54 (1): 299-303. http://dx.doi.org/10.1016/0091-3057(95)02158-2

2. Graham, J., Ramirez, A., Love, S., Richards, M., Burgess, C. (2002). Stressful life experiences and risk of relapse of breast cancer: observational cohort study. Brit. Med. J. 324 (7351): 1420-1424. http://dx.doi.org/10.1136/bmj.324.7351.1420 PMid:12065263 PMCid:PMC115851

3. Lillberg, K., Verkasalo, P. K., Kaprio, J., Teppo, L., Helenius, H., Koskenvuo, M. (2003). Stressful life events and risk of breast cancer in 10,808 women: a cohort study. Am. J. Epidemiol. 157 (5): 415-423. http://dx.doi.org/10.1093/aje/kwg002 PMid:12615606

4. Kyrou, I., Tsigos, C. (2007). Stress mechanisms and metabolic complications. Horm. Metab. Res. 39 (6): 430-438.

http://dx.doi.org/10.1055/s-2007-981462 PMid: 17578760

5. Kruk, J., Aboul-Enein, H.Y. (2004). Psychological stress and the risk of breast cancer: a case-control study. Cancer Detect. Prev. 28 (6): 399-408. http://dx.doi.org/10.1016/j.cdp.2004.07.009 PMid:15582263

6. Armaiz-Pena, G.N., Lutgendorf, S.K., Cole, S.W., Sood, A.K. (2009). Neuroendocrine modulation of cancer progression. Brain Behav. Immun. 23 (1): $10-15$.

http://dx.doi.org/10.1016/j.bbi.2008.06.007

PMid:18638541 PMCid:PMC2630522
7. Lutgendorf, S.K., Sood A. K. (2011). Biobehavioral factors and cancer progression: physiological pathways and mechanisms. Psychosom. Med. 73(9): 724-730.

http://dx.doi.org/10.1097/PSY.0b013e318235be76 PMid:22021459 PMCid:PMC3319047

8. Rabin, B.S (1999). Stress, immune function and health: the connection. New York, NY: Wiley-Liss Sons Inc.

9. Yang, E.V., Glaser, R. (2003). Stress-induced immunomodulation: implication for tumorigenesis. Brain Behav. Immun. 17, 37-40. http://dx.doi.org/10.1016/S0889-1591(02)00064-8

10. Reiche, E.M., Nunes, S.O., Morimoto, H.K. (2004). Stress, depression, the immune system, and cancer. Lancet Oncol. 5, 617-625. http://dx.doi.org/10.1016/S1470-2045(04)01597-9

11. Azpiroz, A., De Miguel, Z., Fano E. Vegas O. (2008). Relations between different coping strategies for social stress, tumor development and neuroendocrine and immune activity in male mice. Brain, Behav. Immun. 22, 690-698.

http://dx.doi.org/10.1016/j.bbi.2007.10.007

PMid:18061400

12. Selye, H. (1936). A syndrome produced by diverse nocious agentes. Nature 138, 32.

http://dx.doi.org/10.1038/138032a0

13. Neylan, T. C. (1998). Hans Selye and the field of stress research. Neuropsychiatry Classics 10 (2): 230-231. http://dx.doi.org/10.1176/jnp.10.2.230

14. Breazile, J.E. (1987). Physiologic basis and consequences of distress in animals. J. A. V. M. A. 191 (10): 1212-1215.

15. Casey, R. (2002). Fear and stress in companion animals. In: D. Horwitz, D. Mills, S. Heath, (Eds.), BSAVA Manual of Canine and Feline Behavioural Medicine (pp. 144-153). Gloucester, UK: British Small Animal Veterinary Association PMid:12124759

16. Le Roith, D., Shiloach, J., Roth, J. (1982). Is there an earlier phylogenetic precursor that is common to both the nervous and endocrine systems? Peptides 3, 211-215. http://dx.doi.org/10.1016/0196-9781(82)90080-8

17. Black, H.P. (1994). Immune system-central nervous system interaction: effect and immunomodulatory consequences of immune system mediators on the brain. Antimicrob. Agents Ch. 38 (1): 7-12. http://dx.doi.org/10.1128/AAC.38.1.7

18. Dantzer, R., Kelley, K.W. (1989). Stress and immunity: an integrated view of relationships between the brain and the immune system. Life Sci. 44 (26): 1995-2008. http://dx.doi.org/10.1016/0024-3205(89)90345-7 
19. Dunn, G. P., Old, L. J., Schreiber, R. D. (2004). The immunobiology of cancer immunosurveilance and immunoediting. Immunity 21, 137-148.

http://dx.doi.org/10.1016/j.immuni.2004.07.017 PMid:15308095

20. Lang, K., Entschladen, F., Weidt, C., Zaenker, K. (2006). Tumor immune escape mechanisms: impact of the neuroendocrine system. Cancer Immunol. Immun. 55 (7): 749-776.

http://dx.doi.org/10.1007/s00262-006-0126-x PMid:16435128

21. Antoni, M.H., Lutgendorf, S.K., Cole, S.W., Dhabhar, F.S., Sephton, S.E., Green McDonalc, P., Stefanek, M., Sood Anil, K. (2006). The influence of bio-behavioural factors on tumours biology: pathways and mechanisms. Nat. Rev. Cancer 6 (3): 240-248. http://dx.doi.org/10.1038/nrc1820 PMid:16498446 PMCid:PMC3146042

22. Ben-Eliyahu, S. (2003). The promotion of tumor metastasis by surgery and stress: Immunological basis and implication for psychoneuroimmunology. Brain Behav. Immun. 17, 27-37. http://dx.doi.org/10.1016/S0889-1591(02)00063-6

23. Thaker, P.H., Sood, A.K. (2008). Neuroendocrine influences on cancer biology. Semin. Cancer Biol. 164-170. http://dx.doi.org/10.1016/j.semcancer.2007.12.005

24. Kiecolt-Glaser, J.K., Preacher, K.J., MacCallum, R.C., Atkinson, C., Malarkey, W.B., Glaser, R. (2003). Chronic stress and age-related increases in the proinflammatory cytokine IL-6. Proceedings of the National Academy of Sciences, 100, (pp. 9090-9095). US

http://dx.doi.org/10.1073/pnas. 1531903100 PMid:12840146 PMCid:PMC166443

25. Mills, D. S., Dube, M. B., Zulch, H. (2012). Stress and pheromonatherapy in small animal clinical behaviour. Oxford: Wiley-Blackwell. http://dx.doi.org/10.1002/9781118702642

26. Mills, D., Karagiannis, C., Zulch, H. (2014). StressIts effects on health and behavior: A guide for practitioners. Vet. Clin. N. Am. Small. 44(3): 525-541. http://dx.doi.org/10.1016/j.cvsm.2014.01.005 PMid:24766698

27. Overall, K.L. (1997). Clinical behavioral medicine for small animals (pp. 209-250). St. Louis: Mosby-Year Book Inc.

28. Berteselli, G., Servida, F., Dall'Ara, P., Verga, M., Piola, E., Puricelli, M., Palestrini, C., (2005). Evaluation of immunological, stress and behavioural parameters in dogs (Canis familiaris) with anxietyrelated disorders. In: D. Mills, E. Levine, G. Landsberg, A.E. Horwitz, A.E. Duxbury (Eds.), Current Issues and Research in Veterinary Behavioral Medicine (pp. 18-22). USA: Purdue Press.
29. Debenedetti, A. (1998). Endocrinologia. In: G. Aguggini, V. Beghelli, L. F. Giulio (Eds), Fisiologia degli Animali Domestici (pp. 645-748). Torino: UTET.

30. Veissier, I., Boissy, A. (2007). Stress and welfare: two complementary concepts that are intrinsically related to the animal's point of view. Physiol. Behav. 92 (3): 429-433.

http://dx.doi.org/10.1016/j.physbeh.2006.11.008 PMid:17182067

31. Overall, K. L. (2000). Natural animal models of human psychiatric conditions: assessment of mechanism and validity. Prog. Neuro-Psychoph. 24(5): 727-776. http://dx.doi.org/10.1016/S0278-5846(00)00104-4

32. Takahashi, T., Ikeda, K., Ishikawa, M., Kitamura, N., Tsukasaki, T., Nakama, D., Kameda, T. (2005). Anxiety, reactivity, and social stress-induced cortisol elevation in humans. Neuroendocrinol. Lett. 26(4): 351-354. PMid:16136010

33. MacEwen, E. G. (1990). Spontaneous tumors in dogs and cats: models for the study of cancer biology and treatment. Cancer Metast. Rev. 9 (2): 125-136. http://dx.doi.org/10.1007/BF00046339 PMid:2253312

34. Vail, D.M., MacEwen, E.G. (2000). Spontaneously occurring tumors of companion animals as models for human cancer. Cancer Invest. 18 (8): 781-792. http://dx.doi.org/10.3109/07357900009012210 PMid:11107448

35. Borgatti, A, Buracco, P. (2009). Un legame che va oltre l'amicizia: cane, uomo ed oncologia comparata. Veterinaria. 23 (2): 9-25.

36. Lagadic, M. (2006). I diversi fattori predisponenti le neoplasie. In: AA. Vv., Oncologia pratica del cane e del gatto (pp 9-13). Collana di Summa - animali da compagnia. Milano: Le Point Vétérinaire Italie.

37. Glaser, R., Kiecolt-Glaser, J. (2005). Stress-induced immune dysfunction: implications for health. Nat. Rev. Immunol. 5, 243-251. http://dx.doi.org/10.1038/nri1571 PMid:15738954

38. Danzer, R., Mormede, P. (1981). Pituitary adrenal consequence of adjunctive behaviours in pigs. Horm. Behav. 15, 386-395. http://dx.doi.org/10.1016/0018-506X(81)90003-9

39. Ohl, F., Arndt, S. S., van der Staay, F. J. (2008). Pathological anxiety in animals. Vet. J. 175, 18-26. http://dx.doi.org/10.1016/j.tvj1.2006.12.013 PMid:17321766

40. Cannas, S., Frank, D., Minero, M., Aspesi, A., Benedetti, R., Palestrini, C. (2014). Video analysis of dogs suffering from anxiety when left home alone and treated with clomipramine. Journal of Veterinary Behavior: Clinical Applications and Research 9(2): 50-57. http://dx.doi.org/10.1016/j.jveb.2013.12.002 
41. Godbout, M., Beauchamp, G., Palestrini, C., Frank, D. (2007). Puppy behavior at the veterinary clinic: a pilot study. J. Vet. Behav.: Clin. Appl. Res. 2, 126-135. http://dx.doi.org/10.1016/j.jveb.2007.06.002

42. Palestrini, C., Minero, M., Cannas, S., Rossi, E., Frank, D. (2010a). Video analysis of dogs with separation-related behaviors. Appl. Anim. Behav. Sci. $124,61 \mathrm{e} 67$

43. Flannigan, G., Dodman, N. H. (2001). Risk factors and behaviors associated with separation anxiety in dog. J. A. V. M. A. 219 (4): 460-466.

http://dx.doi.org/10.2460/javma.2001.219.460

44. McGreevy, P. D., Masters, A. M. (2008). Risk factors of separation-related distress and feed-related aggression in dogs: additional findings from a survey in Australian dog owners. Appl. Anim. Behav. Sci. 109, 320-328.

http://dx.doi.org/10.1016/j.applanim.2007.04.001

45. Godbout, G.P., Glaser, R. (2006). Stressinduced immune dysregulation: implications for wound healing, infectious disease and cancer. J. Neuroimmune Pharmacol. 1 (4): 421-427. http://dx.doi.org/10.1007/s11481-006-9036-0 PMid: 18040814

46. MacEwen, B. S. (2008). Central effects of stress hormones in health and disease: understanding the protective and damaging effects of stress and stress mediators. Eur. J. Pharmacol. 583 (2-3): 174-185.

http://dx.doi.org/10.1016/j.ejphar.2007.11.071

PMid:18282566 PMCid:PMC2474765
47. Skandarkumar, S., Stodulski, G., Hau, J. (1995). Salivary IgA: a possible stress marker in dogs. Anim. Welfare 4 (4): 339-350.

48. Beerda, B., Schilder, M.B.H., van Hooff, J.A.R.A.M., de Vries, H.W., Mol, J.A. (2000). Behavioural and hormonal indicators of enduring environmental stress in dogs. Anim. Welfare 9, 49-62.

49. Yang, Y., Koh, D., Ng V., Lee, C.Y., Dong, F., Goh, S.H., Anantharaman, V., Chia, S.E. (2002). Self-perceived work related stress and the relation with salivary IgA and Lysozyme among emergency department nurses. Occup. Environ. Med. 59, 836-841. http://dx.doi.org/10.1136/oem.59.12.836 PMid:12468751 PMCid:PMC1763606

50. Ng, V., Koh, D., Mok, B.Y.Y., Chia, S.E., Lim, L.P. (2003). Salivary biomarkers associated with academic assessment stress among dental undergraduates. J. Dent. Edu. 67(10): 1091-1094. PMid:14587673

51. Frick, L.R., Rapanelli, M., Cremaschi, G. A., Genaro, A. M. (2009). Fluoxetine directly counteracts the adverse effects of chronic stress on $\mathrm{T}$ cell immunity by compensatory and specific mechanisms. Brain Behav. Immun. 23 (1): 36-40. http://dx.doi.org/10.1016/j.bbi.2008.06.010 PMid:18625298 